\title{
Política Industrial e Divisão Internacional de Trabalho
}

Industrial policies and international division of labor

CARLOS AGUIAR DE MEDEIROS *; *

RESUMO: Este artigo examina a evolução das políticas industriais, estratégias tecnológicas e especialização do comércio em cadeias de valores globais (GVC) na produção industrial liderada por corporações transnacionais e por políticas industriais. Argumenta que a inserção no GVC não constitui uma alternativa mais fácil de atalho tecnológico ao sistema nacional de inovação e à estratégia de desenvolvimento nacional que historicamente têm sido as principais alavancas para o catch-up tecnológico.

PALAVRAS-CHAVE: Desenvolvimento econômico; Política industrial; Cadeias de valor globais; Sistema de inovação.

ABSTRACT: This paper examines the evolution of industrial policies, technological strategies and trade specialization in global values chains (GVC) in manufacturing production led by transnational corporations and by industrial policies. It argues that insertion in GVC does not constitute an easier technological shortcut alternative to national system of innovation and for national development strategy that historically have been the main levers for technological catch-up.

KEYWORDS: Economic development; Industrial policy; Global value chains; Innovation system.

JELClassification: O14; O19; O25; O43.

\section{INTRODUÇÃO}

Ao longo dos anos 1990 afirmou-se entre diversos países em desenvolvimento (PD) especialmente na América Latina, a proposição defendida por Gary Becker (1985) de que a melhor política industrial - entendida como o conjunto de políticas seletivas visando à promoção de setores ou atividades econômicas estratégicas - é

\footnotetext{
* Professor Titular do Instituto de Economia da Universidade Federal do Rio de Janeiro - IE/UFRJ, Rio de Janeiro-RJ, Brasil. E-mail: carlosaguiarde@gmail.com. Submetido: 12/Março/2018; aprovado: 16/ Maio/2018.

** Pesquisador do CNPQ. O autor agradece as sugestões de um parecerista anônimo.
} 
não ter política industrial (Wade, 2015). Tal proposição encontrava amplo respaldo nos documentos do Banco Mundial sobre o grande contraste entre a América Latina e os países do Sudeste Asiático nos anos 1990. Esta interpretação recebeu contundentes críticas de historiadores, sociólogos e economistas a partir das análises como as de Chalmers Johnson (1982), Robert Wade (1990), Ha-Joon Chang (1994) e Alice Amsden (1989), evidenciando que as economias dinâmicas da Ásia desenvolveram capacitações tecnológicas em setores e atividades distantes de suas dotações de fatores através de dinâmicos sistemas nacionais de inovação (SNI) (Freeman, 1995; Lundval; 1992, Nelson, 1993). Entretanto, a crise asiática de 1997 renovou a crítica liberal à política industrial associada ao protecionismo e ao favoritismo deslocando o eixo propositivo para a reforma das instituições.

A despeito deste ataque político e ideológico a política industrial seguiu presente nas últimas décadas (ainda que muitas vezes de forma 'escondida') entre diversas economias asiáticas e entre os países industrializados elas ganharam particular alento sobretudo a partir de 2008 particularmente nos EUA e na Alemanha. Ao mesmo tempo e em reação à expansão comercial chinesa, os EUA realizaram ampla ofensiva comercial através de acordos bilaterais e multilaterais de investimento reforçando no plano doutrinário a crítica à política industrial que aberta ou veladamente começou a se expandir pós-2008.

Entretanto, não apenas a crítica da política industrial advinda dos defensores do livre comércio veio se afirmando nos últimos anos. Duas outras críticas têm sido dirigidas contra a "velha" política industrial. A primeira se coloca no plano microeconômico e institucional sustentando a proposição de que ter-se-ia afirmado na economia global um "capitalismo de alianças" (Dunning, 1997; Baldwin, 2011) baseado na cooperação entre as firmas e os governos. Nesta formulação, que tem como base o comércio entre firmas articuladas em cadeias globais de valor (CGV) lideradas por Empresas Transnacionais (ETN), a política seletiva e de promoção de firmas nacionais teria perdido eficácia econômica e a criação de políticas facilitadoras a uma industrialização verticalmente especializada (IVE) através de 'engate' nas CGV torna-se a estratégia mais adequada e mais rápida de acercamento tecnológico. Ao lado desta perspectiva outros autores próximos ao mainstream acadêmico inclusive no Banco Mundial como Justin Lin (Lin \& Chang, 2009) reconheceram nos últimos anos a importância de uma nova política industrial através de instrumentos e metas distintos da "velha política industrial" (Chang \& Andreoni, 2016) e sob muitos ângulos convergente com a abordagem do "capitalismo de alianças”.

Situada no campo heterodoxo da economia do desenvolvimento a perspectiva analítica do "novo desenvolvimentismo" (Bresser-Pereira, 2010, 2015; Frenkel \& Rapetti, 2015) embora aceite a importância da política industrial seletiva argumenta que nas economias de renda média a variável industrial estratégica é o nível da taxa real de câmbio devido aos seus efeitos sobre a demanda e competitividade do setor industrial; o papel da política industrial seletiva é coadjuvante.

Discute-se neste texto a atualidade da política industrial seletiva analisando a primeira crítica acima resumida sobre a política industrial e os seus desdobramen- 
tos. Argumenta-se que uma política industrial abrangente (que se confunde com uma política de desenvolvimento) é essencial no atual contexto da divisão internacional do trabalho; o mero engate das empresas domésticas nas CGV torna o país tecnologicamente atrasado prisioneiro de uma 'industrialização rasa' (Baldwin, 2011) reforçando em novas bases a dicotomia centro-periferia.

O presente texto contém quatro sessões além desta introdução. A primeira discute a partir das formulações dos autores clássicos da economia do desenvolvimento e de algumas experiências nacionais do pós-guerra as políticas industriais e seus condicionantes políticos; a segunda discute a evolução recente dos padrões de comércio, os fluxos de investimento direto estrangeiro (IDE) e a formação das CGV; a terceira discute a retomada recente da política industrial e os limites da Industrialização Verticalmente Integrada (IVI); a quarta sessão conclui o texto.

\section{A DIFUSÃO DA INDUSTRIALIZAÇÃO NO PÓS-GUERRA E A POLÍTICA INDUSTRIAL}

$\mathrm{Na}$ história do capitalismo industrial, em particular nas economias de industrialização tardia, a política industrial - entendida como qualquer intervenção seletiva visando favorecer setores e atividades produtivas que oferecem melhores perspectivas para o desenvolvimento econômico do país (Pack \& Saggi, 2006) - contou com uma multiplicidade de instrumentos criados pelo Estado visando compensar as desvantagens absolutas do país decorrente do hiato tecnológico, do reduzido mercado interno e do poder financeiro das grandes empresas sediadas nas economias avançadas. Seu objetivo era localizar no espaço nacional um conjunto de relações interindustriais através de indústrias com alto encadeamento para a frente e para trás (Hirschman, 1958). A existências de economias externas, a indivisibilidade tecnológica e a complementaridade dos sistemas produtivos demandaram mecanismos de coordenação dos investimentos e ampla estratégia de desenvolvimento. Nesta, o investimento em infraestrutura, a formação de recursos humanos qualificados, a criação de empresas públicas na indústria pesada, a abertura seletiva ao capital estrangeiro e a criação de bancos públicos de desenvolvimento, estiveram sempre presentes nas experiências nacionais exitosas (Amsden, 2001; Farfan, 2005).

Ainda que na 'industrialização por cópia de técnicas' que se afirmou no auge do desenvolvimentismo entre 1950 e 1980, a principal forma de modernização tecnológica estivesse incorporada nos novos bens de capital, a criação de instituições públicas de pesquisa, e o desenvolvimento de capacitações tecnológicas complementares deu impulso à formação de Sistemas Nacionais de Inovação (SNI) (Freeman, 1995; Nelson, 1993) ${ }^{1}$. Conforme observaram Cimoli e Porcile (2016); a

\footnotetext{
${ }^{1}$ É importante distinguir aqui os elementos materiais e imateriais da tecnologia. "Knowledge contains two dimensions: a "public" one, taking the shape of information easily codified in patents, blueprints, textbooks, etc.; and a "tacit" one, embodied in routines, skills, competencies, and specific practices
} 
difusão da tecnologia é sempre acompanhada por inovações menores e sequenciais que ao longo do tempo fazem importante diferença sobre a competividade das indústrias. Os países que de fato se industrializaram ou, para usar uma expressão do Baldwin (2011), obtiveram uma 'industrialização com significado', implantaram importantes núcleos do setor de bens de capital e de bens intermediários integrando a estrutura produtiva industrial moderna.

Uma notável diferenciação entre as economias do Sudeste Asiático e as demais que se industrializaram neste período foi a maior presença nas primeiras de empresas nacionais na indústria moderna e menor penetração das ETN; nas demais foi muito maior a presença do capital estrangeiro. Esta diferenciação possui grande influência sobre a formação dos SNI desenvolvida nestes países² .

A estratégia industrialista contou nos casos bem-sucedidos com dois processos essenciais, mercados em expansão e Estados Desenvolvimentistas com forte poder político.

A extensão do mercado, tal como analisado por Adam Smith, constitui dimensão essencial para a diversificação produtiva e o seu ritmo de expansão é o principal determinante da taxa de investimento privado ${ }^{3}$. Embora as exportações sejam a principal fonte sustentável de divisas (Medeiros \& Serrano, 2001), o seu peso na demanda final depende de circunstâncias estruturais, políticas e geopolíticas relativamente autônomas. De um lado pontificaram-se os países, como o Brasil, cujo êxito entre 1950 e 1980 baseou-se na força do seu mercado interno, de outro destacaram-se aqueles como os do Sudeste Asiático em que as exportações, foram o principal indutor das novas atividades e importante componente da demanda industrial.

A política industrial em que os investimentos públicos tiveram importância crucial foi a política essencial dos Estados Desenvolvimentistas (Medeiros, 2010), um estado a serviço dos grandes blocos de capitais industriais, mas que possuía

\footnotetext{
(Nelson \& Winter 1982). The public aspect is costly to create but costless to transfer or to make available to others once it has been created. By contrast, the tacit one is not so easily transferred, being the result of different learning processes: learning by doing, by using, by searching, by imitation, by interaction, and by cooperation" (Vertova, 2014, p. 5).

${ }^{2}$ Como as filiais das ETN investem pouco em P\&D, nos PD em que a parcela destas empresas na indústria moderna é alta, o investimento privado em P\&D tende a ser também muito reduzido em comparação com os PD em que a indústria moderna é nacional. A China é uma exceção parcial desta regra. Isto porque em geral o investimento das ETN não ocorre através de filiais em que o controle é $100 \%$ estrangeiro, mas em joint ventures com empresas estatais. Presentemente ao lado dos laboratórios e centros tecnológicos derivados destes empreendimentos as estratégias das firmas chinesas incluem a aquisição de firmas americanas e europeias de alta tecnologia.

${ }^{3}$ Fugiria ao escopo do presente artigo uma discussão sobre as diversas teorias sobre a taxa de investimento. Segue-se aqui a perspectiva do crescimento liderado pela demanda em que os investimentos privados são induzidos pelo crescimento dos componentes autônomos da demanda agregada que não geram capacidade produtiva ao setor privado como os gastos do governo, as exportações e o consumo das famílias. Para uma apresentação e discussão desta perspectiva ver Cesaratto, Serrano e Stiratti (2003) e Deleidi e Mazzucato (2018).
} 
uma agenda de longo prazo em que a afirmação da nação no contexto internacional constituía um componente ideológico essencial. Tendo em vista a natureza intrinsecamente política da política industrial, discriminando setores e atividades e definindo vencedores e perdedores (Chang \& Andreoni, 2016), esta só se afirmou nos países em que os grupos industriais articulados com as burocracias civis e militares reuniram suficiente poder político neutralizando o poder de veto das demais frações de interesses dos grupos dominantes (Hirschman, 1968). Sobre este aspecto a guerra e a posição geopolítica dos países (após a II GM) foi um 'primum mobile' para a política deliberada de desenvolvimento e para as exportações industriais dos países do Sudeste da Ásia como Japão, Coreia do Sul e Taiwan. Para Rússia, China, Vietnã, Índia, Israel não apenas a guerra ou a ameaça de guerra foram agentes catalisadores para a industrialização, mas as capacitações técnicas emanadas de seus complexos industrial-militar foram fatores propulsores para a indústria moderna como na aeronáutica e no setor de bens de capital.

Como notou Robert Wade (2015), foram muito poucas as nações não ocidentais que se tornaram desenvolvidas desde a Primeira Revolução Industrial - Japão, Rússia, Taiwan, Coreia do Sul, Cingapura, Hong-Kong, Israel - em todas duas condições em comum: inimigos externos ao Estado ameaçando a integridade de seu território e uma autoridade pública com grande capacidade de liderar o processo de mudança.

De uma forma geral, os estados desenvolvimentistas particularmente impulsionados por esta coerção política ${ }^{4}$ promoveram a criação de amplas capacitações tecnológicas que transcenderam setores específicos através de laboratórios, centros de pesquisa, educação e treinamento, financiamento e coordenação (Mazzucato, 2013; Medeiros \& Trebat, 2014) gerando "capacitações sociais ou Sistemas Nacionais de Inovação (SNI) (Freeman, 1985, Nelson, 1993).

O auge da formação dos Estados Desenvolvimentistas foi o período da 'Golden Age' do capitalismo central iniciado no pós-guerra e o seu declínio nos anos 1990 correspondeu ao declínio do Estado do Bem-Estar ocorrido nas economias avançadas; mas tal como ocorreu com a evolução deste último, o declínio nem foi total nem muito menos igual entre as economias em desenvolvimento. Algumas sob o peso da dívida externa desmontaram suas instituições promotoras e buscaram, numa direção defendida pelos EUA e as instituições do Consenso de Washington, se integrar ao novo esquema da divisão internacional do trabalho e às novas regras de investimento e financiamento através da abertura unilateral.

Ao lado desta estratégia 'integracionista' (Amsden, 2001), afirmou-se em al-

\footnotetext{
${ }^{4}$ As análises sobre os estados desenvolvimentistas iniciadas com Chalmers Johnson (1982) sobre o Japão adotam em geral uma perspectiva weberiana em que uma tecnocracia relativamente isolada dos grupos privados movida por missões lidera os mercados através de incentivos associados a desempenho. Do nosso ponto de vista as características de organização e de poder observadas em determinados estados desenvolvimentistas foram fortemente condicionadas por processos revolucionários ou pela guerra gerando condições especiais de poder favorecendo o capital produtivo e o desenvolvimento nacional submetendo outras frações de interesses.
} 
guns países uma estratégia 'independente' com maiores controles sobre os fluxos de capitais e novos instrumentos em apoio a empresas e atividades consideradas estratégicas. Desse modo, a reação às transformações lideradas pelos EUA foi muito desigual.

No novo milênio objetivo fundamental da política industrial não mudou, mas a transformação produtiva e a redução do hiato tecnológico que constitui o seu objetivo central, não se faz mais pelo menos entre os PD com maior grau de industrialização através do transplante de setores como a que ocorreu no pós-guerra. A Terceira Revolução Industrial baseada na tecnologia de informação e comunicação (TIC) se caracteriza por seu extraordinário impacto sobre os bens de capital e bens duráveis de consumo e serviços típicos da Segunda Revolução Industrial bem como pela introdução de novos bens, novos serviços e novos processos produtivos (nanotecnologia, digitalização, automação, impressão 3D). Como observou Lall (2004), a combinação entre rápida mudança tecnológica e redução das distancias aumentou fortemente a concorrência e a pressão para a adoção de novas tecnologia e das "melhores práticas" mesmo nas atividades tradicionais.

O desafio tecnológico para os PD é o do fortalecimento dos seus SNI e demais políticas industriais que permitam explorar novas oportunidades tecnológicas, gerar novas capacitações e ampliar o adensamento da estrutura intersetorial integrando as atividades das cadeias produtivas a montante dos bens finais. Este desafio é não só tecnológico, mas sobretudo político.

Para examinarmos este desafio convém considerar brevemente as transformações recentes na divisão internacional de trabalho (DIT).

\section{INVESTIMENTO DIRETO ESTRANGEIRO (IDE) E A FORMAÇÃO DAS CGV}

O sentido principal do IDE na indústria de transformação, tal como destacado por Stephen Hymer (1976) e Raimond Vernon (1966) é o controle sobre ativos intangíveis que permitem a apropriação pelas ETNs das rendas derivadas do progresso técnico. Ao longo dos anos 1960 e 1970, com exceção da busca por recursos naturais estratégicos o principal fluxo de IDE voltado aos PD na indústria de transformação destinava-se à busca de mercado. O sentido principal era pular a barreira protecionista e participar da expansão dos mercados internos e ao mesmo tempo proteger os ativos intangíveis.

Nos anos 1990, duas grandes mudanças ocorreram, o boom e a difusão das TIC e a abertura comercial, financeira e de investimentos nos PD. Este duplo movimento permitiu ampliar a divisão de tarefas na produção de bens e serviços e consequentemente o comércio de produtos intermediários articulados em CGV. Esta transformação resultou na ampliação do IDE tanto para os serviços de comunicação e serviços financeiros - previamente regulados e protegidos - quanto para o setor industrial. A redução dos custos de transporte de bens e de informação não anulou, entretanto, os custos associados à distância geográfica e às vantagens da proximidade dos centros de consumo e dos clusters produtivos, fazendo das CGV 
uma construção predominantemente regional em que a Alemanha na Europa Oriental, os EUA na América do Norte e o Japão no Leste Asiático (e agora crescentemente a China) afirmaram-se como importantes centros de gravidade e de adensamento das cadeias de formação de valor (Balwin, 2011).

A principal contribuição do IDE para a produtividade industrial em PD é a difusão de tecnologias de fabricação. Esta difusão vem se dando num contexto de ampliação da concorrência entre produtores pela redução dos custos de produção, em particular do custo de trabalho. Num outro plano da concorrência amplia-se o controle das ETN sediadas nos países centrais sobre direitos de propriedade intelectual e sobre as rendas da inovação nas CGV (Medeiros \& Trebat, 2017). Estes processos ampliaram os diferenciais de escala da grande empresa necessários para explorar uma marca global (Smith, 2004) e as barreiras tecnológicas. Este processo ao lado do crescente domínio das "altas finanças" suscitou intenso processo de centralização de capital ${ }^{5}$.

Do ponto de vista macroeconômico a contribuição do IDE para o balanço de pagamentos dos PD é fortemente dependente da relação entre os fluxos de ingresso de novo capital e o estoque de capital estrangeiro que gera as transferências para os proprietários dos ativos. Como este fluxo segue a taxa de investimento é esta taxa que governa o seu fluxo. Em relação à direção do balanço de divisas as evidências sugerem (Akyus, 2015) que o IDE voltado para o mercado interno (como historicamente no Brasil e presentemente na China e na Índia) possui um impacto negativo tendo em vista sua maior propensão a importar; já o IDE associado à formação de cadeias produtivas possui um impacto positivo sobre as exportações líquidas, entretanto, não sobre o valor adicionado associado a estas exportações (ver seção seguinte).

\section{SISTEMAS NACIONAIS DE INOVAÇÃO E A EVOLUÇÃO NAS CGV, NOVOS DESAFIOS DA POLÍTICA INDUSTRIAL}

Após 2008, afirmou-se na economia mundial uma menor taxa de crescimento e uma contração da razão de comércio. É neste contexto que se deve considerar a retomada da política industrial. Um contexto que tem na trajetória chinesa, tanto pelo que ela apresenta como experiência quanto pelo desafio que ela representa aos demais países uma dimensão central. Como recentemente referido por um abrangente relatório do governo chinês publicado em 2015, "China Manufacturing 2025" (CM2025), após a grande crise de 2008 a difusão das novas tecnologias" como a

\footnotetext{
${ }^{5}$ Em estudo recente baseado em 'big data', James Glattfelder (2013), mapeou o controle acionário das corporações globais através de redes de propriedade incluindo tanto o controle direto quanto indireto em 48 países (em 2007), identificando uma extraordinária centralização dos detentores do poder global. No topo da rede de controle proprietário estão os grandes bancos, companhias seguradoras, fundos mútuos, instituições financeiras com matrizes principalmente nos EUA; aqui o terreno inconteste do poder econômico privado mundial.
} 
TCI, a nanotecnologia, biotecnologia, novos materiais e novas fontes de energia estaria tornando obsoletas as antigas formas de produção.

Embora o debate sobre política industrial tenha recrudescido após 2008, nos EUA, na Alemanha a política industrial nunca saiu de cena. Nos EUA ela seguiu firmemente nucleada no departamento de defesa (DARPA), no ministério e institutos de Saúde (National Institutes of Health), no Ministério de Energia (ARPA-E) através de recursos, projetos e laboratórios financiados pelo governo. $\mathrm{O}$ 'complexo acadêmico-industrial-militar’ (Medeiros, 2003; Mazzucato, 2013), responsável pela criação de novos setores e atividades, não sofreu qualquer solução de continuidade e a busca por alternativas energéticas e tecnologias verdes tem ampliado os esforços públicos de inovação. Após a grande crise de 2008, o governo norte-americano tem apoiado indústrias estratégicas e ampliado o financiamento em laboratórios de pesquisa, com destaque para a manufatura aditiva ${ }^{6}$. A Alemanha, por seu turno, já vem adotando uma abrangente política industrial visando a criação de fábricas inteligentes (indústria 4.0) através de sistemas 'cyber physical' integrando informação (big data) com robôs, internet das coisas, manufatura aditiva de forma a concentrar mais e mais sua especialização produtiva na capacidade de inovação (Daudt \& Wilcox, 2016)

$\mathrm{Na}$ China, os gastos em $\mathrm{P} \& \mathrm{D}$, os investimentos em parques tecnológicos, os programas de compras e de financiamento de governo voltados para indústrias de alta tecnologia, tanto na TIC quanto na biotecnologia e energia, o programa espacial e militar (Medeiros \& Trebat, 2014) reafirmaram ainda que com características distintas e maior presença das ETN, o desenho central das políticas industriais e tecnológicas exitosas historicamente praticadas pelo Japão e Coreia.

A Índia, em que pesem as reformas liberalizantes dos anos 1990, também vem desenvolvendo sem qualquer solução de continuidade seu programa espacial e militar e de computadores de alto desempenho (Singh, 2008). Na Coreia, o programa de reestruturação produtiva através da centralização dos Chaebols introduzido a partir da crise de 1997 (Amsden, 2001) retomou em novas bases a política industrial. Em Taiwan e Cingapura as políticas industriais bem como seus Estados Desenvolvimentistas não foram desconstruídas nos anos 1990, suas instituições e mecanismos persistiram e promovendo a modernização tecnológica.

A evolução tecnológica atual coloca novos desafios para a política industrial entre os países distantes da fronteira tecnológica. Como examinado no relatório CM2025, o desafio para o sistema produtivo chinês é evoluir de um sistema industrial centrado na produção industrial com tecnologias importadas para um sistema baseado em inovações com tecnologias próprias ${ }^{7}$. Esta transformação requer um

\footnotetext{
${ }^{6} \mathrm{O}$ National Additive Manufacture Innovation Institute foi recentemente criado para fomentar as novas tecnologias na revolucionária técnica de 3D bem como para desdobramentos na biotecnologia, robótica etc. Ver Daudt e Willcox (2016).

7 "From Made in China to Created in China, from China Speed to China Quality, and from Chinese products to Chinese brands" (CM2025, p. 4).
} 
novo sistema produtivo industrial baseado na digitalização, informatização e articulação em rede. Este sistema caracteriza-se não apenas por ser mais flexível, mas pela maior articulação da produção com as especificações do consumo individualizado. A noção sobre a competitividade sistêmica, mais próxima da perspectiva classicamente desenvolvida por Albert Hirschman $(1958,1968)$ sobre a articulação do sistema produtivo ganha crescente ênfase.

É importante distinguir esta noção sistêmica da competitividade da que se depreende da perspectiva desenvolvida por Hidalgo e Hausman (2009) baseada na especialização a partir de 'espaços do produto' ('product space'), definida a partir das características físicas do produto. Como advertiram Chang e Andreoni (2016), com a fragmentação dos processos produtivos, o elemento chave é o domínio da tecnologia ${ }^{8}$. As classificações usuais baseadas em setores produtivos perdem significado na medida em que abrigam hoje um grau maior de heterogeneidade tecnológica de produtos e atividades. Os fluxos tecnológicos ocorrem entre bens e atividades que se encontram nos mesmos 'domínios de capacitação tecnológica” (Chang \& Andreoni, 2016), isto é, que possuem tecnologias, (máquinas e processos) semelhantes e complementares aproximando do ponto de vista tecnológico a produção de bens e serviços. A partir destes domínios processos manufatureiros classificados segundo a tecnologia e não segundo o produto físico demandam políticas industriais distintas daquelas usuais ${ }^{9}$. Este movimento reforça a importância dos sistemas de inovação abrangentes.

A questão-chave é que estes desafios que dependem da capacidade de coordenação, de financiamento e de determinação do Estado se colocam num momento de baixo crescimento dos investimentos decorrente de políticas de austeridade. Os desastrosos efeitos desta na economia mundial e em especial nas economias periféricas têm ampliado o fosso entre as economias progressivas e as demais ${ }^{10}$. Como observou Mazzucato (2016), as empresas que iniciam nas áreas de TIC, biotecnologia e nanotecnologia enfrentam cenários de muitos anos sem lucro antes dos resultados aparecerem. Isto amplia a importância dos bancos públicos de desenvolvimento numa ponta, e na outra, a força dos oligopólios globais. Neste cenário macroeconômico e na falta destas instituições e de incentivos adequados as estra-

\footnotetext{
${ }^{8}$ Ginsburg, Celi, G.; Guarascio, Simonazzi, (2017) não consideram haver aí um conflito, mas estratégias complementares combinando tanto as capacitações que estejam na vizinhança do processo produtivo (que estejam no espaço produtivo) dos bens que são produzidos num determinado momento quanto daquelas capacitações criadas para a produção de novos produtos. Ver próxima seção.

${ }^{9}$ Como observam Chang e Andreoni (2016, p. 36), a política industrial teria por alvo atividades do mesmo domínio tecnológico, "food processing, advanced materials, mechanics and control systems, ICT, rather than the development of particular industries defined in terms of the final product. Each one of these capability domains constitutes a platform of competencies, technologies, productive knowledge, and experiences that can be deployed in a plurality of sectors".

${ }^{10}$ Para uma análise sobre os efeitos negativos da austeridade sobre o progresso técnico ver Deleide, Mazzucato (2018).
} 
tégias empresariais tendem para tal como sublinhado por Baumol (1990) para atividades improdutivas (especulativas).

Em uma análise contemporânea sobre os Estados Desenvolvimentistas, Robert Wade (2015) considerou o esforço de promoção de firmas domésticas para a posição de fornecedores principais de produtos intermediários para as ETN e mesmo de concorrentes destas, como uma estratégia que ele denomina de 'Estado Desenvolvimentista tipo I' (ED1). Ela estaria hoje plenamente presente na China. Para os PD que não contam com seu mercado interno como ativo de barganha, haveria, entretanto, uma outra estratégia, um 'Estado Desenvolvimentista tipo II' (ED2) em que apenas as políticas horizontais (como as cambiais e incentivos de investimento) poderiam prosperar. Nesta estratégia, a relação com o IDE seria menos discricionária visando deslocamentos dentro das cadeias produtivas sem as expectativas mais abrangentes do Estado Desenvolvimentista I.

Nesta direção, importante parcela da literatura atribui ao IDE e à participação nas CGV lideradas por este investimento um caminho alternativo e possível de modernização tecnológica (Baldwin, 2011; Dunning, 1997). Seria mais prático e efetivo atrair estes fluxos externos de investimento e construir capacitações tecnológicas visando à evolução dentro da cadeia. Os elementos tácitos do progresso técnico seriam mais rapidamente difundidos via as filiais das ETN ou através de contratos e joint ventures. Milberg e Winkler (2013) consideram o progresso nas CGV como uma nova estratégia de crescimento dos países em desenvolvimento, a Industrialização Verticalmente Especializada (IVE). Esta constituiria uma evolução em relação a industrialização por substituição de importações (ISI) e a Industrialização Orientada para Exportações (IOE) $)^{11}$.

A criação de capacitações tecnológicas visando a um progresso nas cadeias produtivas constituiria a principal estratégia e o crescimento da parcela de mercado das empresas e do país nas atividades e funções produtivas de maior conteúdo tecnológico na economia global a medida do seu sucesso. Sair da armadilha da especialização em atividades de baixos salários e ampliar o conteúdo doméstico dos produtos e atividades exportadas constituiria o desafio. A construção desta estratégia definiria o escopo essencial da moderna política industrial.

Esta evolução enfrenta duas ordens de questões. A primeira é a do controle das cadeias produtivas, a segunda é da evolução do país ao longo das cadeias. Entre as diferentes formas de progresso nas cadeias de valor (de produto, de processo e funcional) ${ }^{12}$ a mais importante é a criação de capacitações tecnológicas que permita ao país, através de firmas locais mover-se para os estágios das cadeias produ-

\footnotetext{
11 "Now the issue facing firms and government is less that of finding new, more capital-intensive goods to sell to consumers in foreign countries. Instead, it requires moving up though the chain of production of a particular commodity or set of commodities into higher value added activities. This involves raising productivity and skills though mechanization and the introduction of new technologies. It also requires fitting into existing corporate strategies... We might say that in the same way the ISI strategies gave away to EOI, the latter has now given way to VSI efforts aimed at upgrading within GVCs” (p. 240).

12 Para uma tipologia ver Kaplinsky (1998).
} 
tivas associadas ao design e ao marketing (geradoras de rendas diferenciais) e inserir-se em novas cadeias com maior conteúdo tecnológico. A questão-chave é que a estrutura hierárquica das CGV define uma apropriação desigual do progresso técnico favorecendo os detentores de marcas globais, as grandes ETN e varejistas que organizam as cadeias ${ }^{13}$.

$\mathrm{Na}$ indústria de transformação cujas cadeias produtivas são lideradas pelo produtor, como na automobilística e eletrônica (incluindo eletrodomésticos e produtos da TCI), e naquelas cuja liderança é exercida por grandes varejistas, como na indústria de vestuário e calçados ${ }^{14}$, a apropriação do valor é assimetricamente distribuída entre os que detêm as marcas globais, entre as empresas intermediárias que coordenam as empresas terceirizadas e estas últimas contratadas para as diferentes etapas do processo produtivo geograficamente espalhadas na economia global. Em relação às tarefas, a hierarquia se dá entre o trabalho manual - típico nas atividades de montagem e de operação industrial - difundidos para empresas terceirizadas e localizadas nos PD com vantagens de custo direto (do trabalho e demais custos diretos) e o trabalho intelectual típico das atividades de desenho e de comercialização essencialmente exercidas pelas ETNs.

Entre as empresas terceirizadas, o excesso de concorrência decorrente da baixa barreira à entrada e a padronização das atividades rotineiras impõem baixos salários, intensas jornadas de trabalho e baixas margens de lucro (Dedrick, 2010). Estas características se impõem sobre as firmas domésticas subcontratadas e coordenadas por firmas intermediárias segundo contratos governados por firmas detentoras de marcas globais ${ }^{15}$. As ETNs se apropriam das rendas decorrentes das barreiras à entrada associadas às marcas, as rendas da inovação do financiamento e comercialização.

Em geral a literatura sobre evolução nas CGV adota um procedimento dual quando examina a evolução das firmas domésticas nas cadeias produtivas e quando considera a evolução produtiva do país. A diferença no procedimento diz respeito à consideração no primeiro caso, de uma estrutura hierárquica e de poder centrado nas ETN - dimensão intrínseca das CGV e, no segundo caso, considera-se a evolução das especializações do país no âmbito mais amplo da divisão internacional do trabalho independente do controle da propriedade. Em relação ao primeiro plano, o das empresas, uma vasta literatura empírica sobre indústrias em PD discute a afirmação destas redes evidenciando caminhos de modernização tecnológica através de deslocamentos ao longo das cadeias de valor (Humprey \& Schmitz,

\footnotetext{
13 "Firms exerting 'governing function' in a GVC are those that, by erecting high entry barriers around their core activities, are able to capture a high share of value and coordinate the flow of critical market and technological information within the chain" (Farfan, 2005, p. 7).

${ }^{14}$ Estes produtos se assemelham neste particular aos da agricultura em que o comando da cadeia produtiva também é 'liderado pelo consumidor' nas atividades a jusante.

15 "In other words, there is a redistribution of the value produced in the production and distribution chain from the periphery of the global economy to the centre" (Smith, 2003, p. 244).
} 
2002). Como observaram Morrison, Pietrobelli e Rabellotti (2015), raramente a abordagem da CGV explicita como o progresso tecnológico ocorre.

Quando a questão é posta nos países e suas trajetórias nacionais frequentemente, Coreia e Taiwan, são apresentados como exemplos de países que evoluíram ao longo da cadeia produtiva (progresso funcional). Entretanto, tendo em vista a baixa participação das firmas estrangeiras na estrutura produtiva destes países, bem como a estratégia de promoção de firmas nacionais com tecnologias próprias e marcas globais, dificilmente a evolução destes países expressa ou traduz uma evolução construída pelas grandes firmas oligopólicas que tipicamente comandam as CGV. Estes países construíram suas estruturas produtivas e capacitações tecnológicas (Bell \& Pavitt, 1993) a partir de suas empresas num ambiente institucional e social historicamente determinado. Os demais países asiáticos seguiram uma trajetória distinta e muito mais subordinada aos IDE. Nos anos mais recentes, como será discutido mais à frente, o ingresso nas CGV resultou em menores ganhos em termos de valor adicionado e crescimento das exportações ${ }^{16}$.

Buscando uma delimitação mais específica de evolução 'desde dentro' das CGV governadas pelas ETN, convém examinar tanto o grau de participação do país no valor adicionado gerado nas CGV como a sua direção. Os dados da OCDE-OMC sobre o comércio em valor adicionado permitem distinguir a parcela do VA contido nas exportações do país (denotando uma especialização vertical importadora EVI) e a parcela do valor adicionado gerado no país incorporado nas exportações de outros países (especialização vertical exportadora EVX) ${ }^{17}$. A combinação destes dois encadeamentos, a montante e a jusante medidas em VA em proporção às exportações do país, indicaria o grau em que este participa da CGV.

Usando esta base de dados, Caraballo e Jiang (2016) investigaram a evolução do valor adicionado importado e doméstico presente nas exportações de uma ampla amostra de países industrializados e em desenvolvimento e encontraram um declínio de 87\% do VA doméstico entre 1995 e 2009, esta "erosão do valor adicionado" foi muito mais intensa nos PD com maior participação das exportações industriais. Entre os determinantes principais desta evolução estava a importação de produtos intermediários baseados em trabalho qualificado.

Esta divisão internacional do trabalho possui importantes repercussões sobre a distribuição do valor adicionado do comércio e a direção predominante da especialização do país nas CGV se a montante (EVI crescendo mais do que EVX) ou se a jusante. A razão entre a EVX e a EVI denotaria o tipo de contribuição das CGV à especialização do país. Na China a razão EVXIEVI foi de 0,41, do mesmo modo,

\footnotetext{
${ }^{16}$ Como observaram Cassiolato et al., (2015), as abordagens sobre CGV reduzem ou eliminam as diferenças nacionais e os condicionantes que daí derivam.

${ }^{17}$ Esta metodologia é também seguida por Correia (2016). Embora a combinação dos índices de EVI e de EVX seja adequada como grau de integração nas CGV é conveniente distingui-los, pois o índice global subestima a importância das cadeias produtivas em países que como o México exportam especialmente bens finais de consumo para os EUA.
} 
esta razão todos os países do Sudoeste da Ásia, Vietnã e plataformas exportadoras como o México a razão foi menor do que $1^{18}$. Nos EUA e no Japão a direção é inversa, com as razões atingindo respectivamente 2,53 e 2,23.

Estes dados revelam que as exportações industriais dos PD que se engataram nas CGV incorporaram uma fração de valor adicionado estrangeiro (essencialmente proveniente das economias avançadas) muito superior ao valor adicionado doméstico presente nas exportações de outros países. Esta inserção traduz as grandes diferenças salariais e tecnológicas entre as economias avançadas e os PD.

Entretanto, pode-se argumentar que se o VA doméstico associado às exportações estiver crescendo, independentemente de haver saldo negativo, o país estaria se beneficiando de sua integração nas CGV. Usando este critério a China fortemente se destaca. Em contraste com o que se passou na Coreia onde houve uma diminuição do VA doméstico nas suas exportações entre 2005 e 2009, ou no México onde houve um pequeno aumento, na China o aumento desta parcela do VA doméstico foi de 11,8\% (Banga, 2013).

É, portanto, a taxa de crescimento do VA doméstico contido nas exportações do PD o principal desafio para a política industrial nos setores e atividades em que as CGV são predominantes. Este desafio, o de conter a erosão do valor adicionado doméstico vai se ampliando à medida que o país se industrializa e se desloca para atividades mais complexas em que não apenas o conteúdo de emprego, mas a parcela do VA doméstico contido nas exportações é menor.

Sair do caminho de especialização baseada em baixos salários (low-road) e através de políticas industriais promover um progresso tanto econômico como social (high-road) constituiria o desafio maior para estas economias, um desafio que a rigor não se distingue em termos de esforços tecnológicos dos exercidos pelos países que no pós-guerra se industrializaram com sistemas produtivos menos internacionalizados. A rigor, a questão central é a da inovação tal como sublinhado na literatura sobre os SNI, sem a qual a ideia de progresso ao longo da cadeia produtiva torna-se inexplicável (Humphrey \& Schmitz, 2002, Cimoli, $(2014)^{19}$.

A integração em CGV na ausência de um articulado SNI, reproduz na produção manufatureira a clássica polarização centro-periferia e assimétrica apropriação dos frutos do progresso técnico, para usarmos uma clássica formulação de Raúl Prebisch. Com efeito, nos casos bem-sucedidos de desenvolvimento a integração de atividades produtivas e firmas domésticas nas redes de comércio comandadas por ETNs se deu de forma articulada e complementar a industrialização liderada pelo Estado e instituições públicas e privadas voltada ao conhecimento e inovação (Cas-

\footnotetext{
18 Naturalmente que os países que exportam recursos naturais como a Indonésia, Brasil, Rússia etc possuem um indicador maior do que um devido a muito menor participação de componentes importados na exportação de commodities. Mas a o foco aqui é a indústria de transformação e a indústria nestes países, com a exceção da Indonésia está muito pouco integrada nas cadeias produtivas.

${ }^{19}$ Como sublinharam Morrison e coautores (2015), a ideia de que o engate nas CGV gera um impacto positivo automático aos produtores locais negligencia o fato de que "[...] local actors have to invest in learning and building technological capability to effectively upgrade” (p. 2).
} 
siolato et al., 2015). Nestas experiências, o setor público exerceu uma função de "cluster broker" promovendo o desenvolvimento de economias externas; facilitando os vínculos interfirmas e fortalecendo a posição das firmas locais nas cadeias de valor.

A questão desafiadora não se resume, como se argumentou, à definição de instrumentos e incentivos ou a delimitação de áreas a serem priorizadas, trata-se antes de uma questão política que viabilize ao Estado poder e coesão social para a construção nas condições atuais de estratégias nacionais voltadas à transformação estrutural.

\section{OBSERVAÇÕES FINAIS}

A expansão extraordinária do comércio de bens intermediários e a formação de cadeias de valor que caracteriza a atual divisão internacional do trabalho decorreu tanto de transformações tecnológicas associadas à TIC como da liberalização do regime de comércio e de investimentos que se afirmou na economia mundial. Como o objetivo central tanto do IDE centralizado nas ETN é o de se apropriar das rendas ao longo das cadeias de valor, a difusão do progresso técnico e a sua apropriação por firmas locais nas ED depende não apenas da sua participação em redes lideradas pelas ETN, mas da existência de instituições e políticas públicas que deliberadamente promovam o aprendizado em tecnologias dominadas e aproveitem as oportunidades tecnológicas tanto para o deslocamento para estágios tecnologicamente mais avançados quanto para a construção de trajetórias produtivas com maior conteúdo e tecnologias nacionais.

Argumentou-se ao longo deste texto que ao contrário da suposição de que a política industrial e os sistemas nacionais de inovação perdem importância ou espaço em decorrência de estratégias focadas na especialização segundo CGV, estas políticas e os sistemas nacionais de inovação tornam-se crescentemente importantes para o prosseguimento do processo de industrialização e modernização tecnológica.

Os países em desenvolvimento (como os países do Sudoeste da Ásia e México) que buscaram se integrar na economia mundial simplesmente removendo restrições ao capital estrangeiro e buscando competitividade externa através de inserção nas cadeias produtivas em atividades industriais com baixos custos do trabalho elevaram substancialmente suas exportações brutas e o emprego industrial, mas o valor adicionado contido em suas exportações caiu de forma substancial. Esta rota de crescimento da produção industrial exportadora não resultou em maior convergência tecnológica, difusão das capacitações tecnológicas e redução das desigualdades. Nestas economias a industrialização resultou ser 'fácil e rápida', mas também 'menos significativa' (Baldwin, 2011). Embora a China seja o PD com maior inserção nas CGV sua abrangente estratégia de desenvolvimento industrial e esforço tecnológico permitiu combinar tanto uma evolução nas cadeias para atividades de 
maior conteúdo tecnológico como modernizar o conjunto da economia. Este desafio tem ampliado seus esforços para ampliação de um abrangente SNI.

Nas experiências exitosas de desenvolvimento política industrial não se limitou a criar um ambiente favorável às firmas domésticas mas induziu o deslocamento das especializações produtivas não apenas no período da Golden Age, sob a liderança de Estados Desenvolvimentistas, mas também no período posterior, em particular após 2008. Nestas experiências argumentou-se que a questão central da política industrial não se confunde com a existência de instrumentos, mas de poder do Estado nacional. Trata-se aqui de uma questão do poder político do Estado tanto em sua negociação com as grandes empresas abrindo oportunidades e espaços para as empresas domésticas quanto em sua capacidade de investir, financiar e promover o desenvolvimento econômico e tecnológico.

\section{REFERÊNCIAS BIBLIOGRÁFICAS}

Akyus, Y (2015) "Foreign direct investment, investment agreements and economic development: Myths and realities". South Centre Research Paper, 63.

Amsden, A. (1989) Asia's Next Giant: South Korea and Late Industrialization. Oxford: Oxford University Press.

Amsden, A (2001) The Rise of the Rest, Challenges to the west from Late-Industrializing Economies. New York: Oxford University Press.

Baldwin, R. (2011) “Trade and industrialization after globalization's $2^{\mathrm{ND}}$ unbundling: how building and joining a supply chain are different and why it matters" NBER Working Paper 17716.

Banga R (2013) "Measuring value in global value chains". UNCTAD Background Paper RVC-8.

Baumol, W. (1990) "Entrepreneurship: productive, unproductive, destructive”. Journal of Political Economy, 98 n 5 pg. 893-921.

Bell M.R. and Pavitt K., (1992), “Technological accumulation and industrial growth: contrasts between developed and developing countries", Industrial and Corporate Change, 2,2, pp.157 - 210.

Caraballo, J. G.; Jiang, X (2016) "Value-added erosion in global value chains: an empirical assessment". Journal of Economic Issues, Vol 1 No 1 March.

Cassiolato, J.; Matos, M. G. P.; Marcellino, I. S.; Podcameni, M. I. (2015), “The myth of upgrading and development through insertion in Global Value Chains: a critique based on the Innovation System Literature" Paper Submitted to 13th Globelics International Conference La Habana, Cuba.

Cesaratto, S.; Serrano, F.; Sirati, A. (2003) "Technical change, effective demand and employment" Review of Political Economy 15 (1).

Cimoli, M. (2014) "National system of innovation: a note on technological asymmetries and catching-up perspectives”. Revista de Economia Contemporânea, vol 18, n1 janeiro-abril p 5-31.

Cimoli, M. Porcile, G. (2016) "Productivity and structural change: structuralism and its dialogue with other heterodox currents”, In Alicia Bárcena, Antonio Prado, Neostructuralism and Heterodox Thinking in Latin Americana and Caribbean in the Early XXI Century, ECALC: Santiago;

Chang, H-J (1994) The Political Economy of Industrial Policy, London: Palgrave Macmillan;

Chang, H-J; Andreoni, A. (2016) "Industrial policy in a changing world: basic principles neglected issues and new challenges". Paper apresentado em conferência 40 Anos de Cambridge Journal of Economics;

China Manufaturing 2025: Putting Industrial Policy Ahead of Market Forces, European Union Chamber of Commerce in China, 2017;

Correa, L. M. (2016) “Trajetórias dos países em desenvolvimento nas cadeias globais de valor: Upgra- 
ding, estágios de desenvolvimento e mudança estrutural”. Tese de doutorado, Instituto de Economia, Universidade Federal do Rio de Janeiro - IE/UFRJ;

Daudt, G.; Willcox, L.D. (2017) "Reflexões críticas a partir das experiências dos EUA e da Alemanha em manufaturas avançadas" BNDES Setorial, 44, pg 5-45;

Dedrick J, Linden, G (2010) "Who profits from innovation in global value chains? A study of the Ipod and Notebook PCs”. Industrial and Corporate Change 19 (1) 81-116;

Deleide, M.; Mazzucato, M. (2018) "Putting austerity to bed: Technical progress, aggregate demand and the supermultiplier”. ISI Growth Working Paper, 2018.

Dunning, J (1997) Alliance Capitalism and Global Business. London e New York: Routledge.

Farfan, O. H. (2005) "Understanding and escaping commodity-dependency: a global value chain perspective”. Paper prepared for the Investment Climate Unit, International Finance Corporation, The World Bank;

Freeman, C. (1995) "The national system of innovation in historical perspective", Cambridge Journal of Economics, vol 19, n 1 pp 5-24

Frenkel, R.; Rapetti, M. (2015) "The real exchange rate as a target of macroeconomic policy". In Rethinking Development Strategies after the Financial Crisis, UNCTAD, Geneva and New York, United Nations;

Gallagher, K. P.; Thrasher, R. D. (2015) "Defending development sovereignty: the case for industrial policy and financial regulation in the trading regime". In Rethinking Development Strategies after the Financial Crisis, UNCTAD, Geneva and New York, United Nations.

Glattfelder, J. B. (2013) Decoding Complexity, Uncovering Patterns in Economic Networks, New York: Springer.

Ginzburg, D; Celi, G.; Guarascio, D. Simonazzi, A. (2017) “A policy divide: industrial policy in core and peripheral countries" EAEPE Conference, Budapest 19-21 October 2017;

Hidalgo, C.; Hausman, R. (2009) "The building blocks of economic complexity", Proceedings of National Academy of Sciences, vol 106, n 26.

Hirschman, A. (1958) The Strategy of Economic Development, Yale University Press.

Hirschman, A. (1968) "The political economy of import-substituting industrialization in Latin America”, The Quarterly Journal of Economics, Vol LXXXII, No 1

Humphrey, J.; Schmitz, H. (2000) "Governance and upgrading: linking industrial cluster and global value chain research" IDS Working Paper, 120.

Humphrey, J.; Schmitz, H. (2002) "How Does insertion in global value chain affect upgrading in industrial clusters?” Regional Studies, vol. 36 p 1017-1027.

Hymer, Stephen H. (1976) The International Operations of National Firms: A Study of Direct Foreign Investment, The MIT Press, Cambridge, Massachusetts; London, England;

Johnson, C. (1982) MITI and the Japanese Miracle, New York, Stanford University Press;

Kaplinsky, R. (1998) "Globalization, industrialization and sustainable growth: the pursuit of the Nth rent" IDS Discussion Paper 365.

Lee, K (2015) "Imitation to innovation: late mover's catch-up and technological leadership change" Paper Submitted to the 13th Globelics International Conference La Habana, Cuba;

Lin, J. \& Chang, H-J (2009) "Should industrial policy in developing countries conform to comparative advantage or defy it?" Development Policy Review, vol 27, n 5.

Lundvall, B-A (1988) "Innovation as an interactive process: from user-producer interaction to the national system of innovation”. In G. Dosi, C. Freeman, R, Nelson, G Silverberg, L. Soete (eds) Technical Change and Economic Theory, London and New York: Pinter Publisher (pp 349-369)

Mazzucato, M (2013) The Entrepeneurial State, Debunking Public vs. Private Sector Myths, London, New York, New Delhi: Anthem Press;

Mazzucato, M. (2016), "Innovation, the state and patient capital”. In Michael Jacobs, Mariana Mazzucato, eds. Rethinking Capitalism. New York: Wiley Blackwell.

Medeiros, C. A. (2003) "The post-war American technological development as a military enterprise", Contributions to Political Economy, 22; 
Medeiros, C. A. (2010) “Auge e declínio dos estados desenvolvimentistas” Parceria Estratégica CGEE, Vol 15, N 30;

Medeiros, C. A. (2017) “Industrialization, trade and economic growth". In Matias Vernengo, ed., Why Latin American Nations Fail, California: University of California Press.

Medeiros, C. A.; Serrano, F (2001) "Inserção externa, exportações e crescimento no Brasil”. In Fiori, J. L.; Medeiros, C. A. Polarização Mundial, Petrópolis: Vozes

Medeiros, C. A.; Trebat, N. (2014) "Military modernization in Chinese technical progress and industrial innovation". Review of Political Economy, Vol 26, n 2, p 303-324;

Medeiros, C. A., Trebat, N. (2017) "Inequality and income distribution in global value chain". Journal of Economic Issues, Vol 51, Issue 2;

Milberg, W.; Winkler, D. (2013) Outsourcing Economics, Global Chains in Capitalist Development. New York: Cambridge University Press;

Morrison, A.; Pietrobelli, C.; Rabellotti, R (2015) "Global value chains and technological capabilities: a framework to study industrial innovation in developing countries". Paper apresentado em PRIN, Dynamic Capabilities between Firm Organization and Local Systems of Production, SPRU, University of Sussex;

Nelson, R., ed. (1993), National Innovation Systems: A Comparative Analysis. Oxford: Oxford University Press;

Pack, H.; Saggi, K (2006) "Is there a case for industrial policy? A critical survey". The World Bank Research Observer 21(2);

Pietrobelli, C.; Rabelloti, R. (2004) "Upgrading Clusters and Value Chains in Latin America: The Role of Policies”. IADB Sustainable Development Department: MSM 124;

Rowthorn, R. (1996) "East Asian development: the flying geese paradigm reconsidered", UNCTAD Study n 8;

Singh, A. (2008) "The past, present and future of industrial policy in India: Adapting to the changing domestic and international environment" Centre for Business Research, University of Cambridge Working Paper No 376;

Smith, T. (2004) "Technology and history in capitalism: Marxian and Neo-Schumpeterian perspectives". In Ricardo Bellofiore and Nicola Taylor, eds. The Constitution of Capital. London: Palgrave Macmillan;

Vernon, R (1966) "International investment and international trade in the product cycle". Quarterly Journal of Economics, 80 (May), 190-207;

Vertova, G. (2014) "The state and the national systems of innovation: a sympathetic critique". Levy Economics Institute Working Paper, No 823;

Wade, R. (1990) Governing the Market: Economic Theory and the Role of the Government in East Asia Industrialization. Princeton: Princeton University Press

Wade, R. (2015) “The Role of Industrial Policy in Developing Countries" in Rethinking Development Strategies after the Financial Crisis, UNCTAD, Geneva and New York, United Nations. 